\title{
Rapid sequence induction for appendectomies: a retrospective case-review analysis
}

\section{Induction en séquence rapide pour appendicectomie: une étude de cas rétrospective}

\author{
Juraj Istvan, MD • Marc Belliveau, MD • \\ François Donati, MD, PhD
}

Received: 18 August 2009/Accepted: 18 December 2009/Published online: 5 January 2010

(C) Canadian Anesthesiologists' Society 2010

\begin{abstract}
Purpose Rapid sequence induction (RSI) with cricoid pressure is suggested to decrease the risk of aspiration of gastric contents. However, the effectiveness of RSI has been questioned, and the technique may lead to airway and hemodynamic complications. The purpose of this study was to determine the frequency of RSI use in patients with acute appendicitis, the types of drugs administered, and the occurrence of any complications.

Methods After approval by the Ethics Committee, the charts of patients undergoing appendectomy in a one-year period were examined retrospectively. Information was retrieved on Mallampati airway evaluation, airway device used, preoxygenation, RSI, and drugs at induction. Reported complications were noted, including airway difficulties, hypotension (systolic blood pressure $<$ $80 \mathrm{mmHg}$ ) and hypertension $(>160 \mathrm{mmHg})$ in the 20-min period after induction.

Results General anesthesia with tracheal intubation was used in 248 of 250 cases reviewed. The Mallampati airway evaluation, preoxygenation, and RSI were recorded as performed in 95, 94, and $81 \%$ of cases, respectively. Opioids, propofol, and neuromuscular blocking agents were given in 98, 98, and 99\% of patients, respectively. Succinylcholine use was common (80\%), with $96 \%$ of these patients receiving rocuronium precurarization. Difficult
\end{abstract}

J. Istvan, MD · M. Belliveau, MD · F. Donati, MD, PhD Département d'Anesthésiologie, Hôpital MaisonneuveRosemont, Université de Montréal, Montréal, QC H3A 1A1, Canada

J. Istvan, MD ( $)$

Royal Victoria Hospital, F9-16, 687, Avenue des Pins Ouest, Montréal, QC H3A 1A1, Canada

e-mail: jristvan@gmail.com intubation with successful alternate technique was encountered in three patients (1.2\%). Hypotension and hypertension occurred in $27 \%$ and $8 \%$ of patients, respectively. There were no documented cases of aspiration. Oxygen desaturation was mentioned in one case at induction and in three cases at emergence.

Conclusion An RSI with opioid, induction agent, and succinylcholine is the technique of choice for appendectomies at our institution. The frequency of airway complications is too low to recommend a change in practice.

\section{Résumé}

Objectif L'induction en séquence rapide (ISR) avec pression cricoidienne est la technique suggérée afin de réduire le risque d'inhalation du contenu gastrique. Cependant, l'efficacité de l'ISR a été remise en question car il se pourrait que cette technique cause des complications au niveau de l'hémodynamie et des voies aériennes. L'objectif de cette étude était de déterminer la fréquence d'utilisation de l'ISR chez les patients souffrant d'appendicite aiguë, le type de médicaments administrés et la survenue de complications.

Méthode Après avoir reçu l'accord du comité d'éthique, les dossiers des patients subissant une appendicectomie au cours d'une période d'un an ont été passés en revue rétrospectivement. Les renseignements tirés des dossiers portaient sur l'évaluation des voies aériennes selon la classe de Mallampati, le dispositif utilisé pour sécuriser les voies aériennes, la préoxygénation, l'ISR et les médicaments utilisés à l'induction. Les complications rapportées ont été notées, y compris les difficultés au niveau des voies aériennes, l'hypotension (tension systolique $<80 \mathrm{mmHg}$ ) et l'hypertension $(>160 \mathrm{mmHg})$ durant la période de $20 \mathrm{~min}$ suivant l'induction. 
Résultats Dans 248 des 250 cas passés en revue, une anesthésie générale avec intubation trachéale a été utilisée. L'évaluation des voies aériennes selon la classe de Mallampati, la préoxygénation et l'ISR ont éténotées comme réalisées dans 95, 94 et $81 \%$ des cas, respectivement. Des opioïes, du propofol et des curares ont été administrés à 98,98 et $99 \%$ des patients, respectivement. L'usage de succinylcholine était courant (80\%), et $96 \%$ de ces patients ont reçu une précurarisation au rocuronium. Une intubation difficile suivie d'une technique alternative réussie a été observée chez trois patients (1,2\%). Il y a eu des cas d'hypotension et d'hypertension chez $27 \%$ et $8 \%$ des patients, respectivement. Aucun cas d'inhalation n'a été documenté. Un cas fait mention de désaturation d'oxygène à l'induction, et trois au réveil.

Conclusion Dans notre institution, la technique de choix pour les appendicectomies consiste en une ISR accompagnée d'un opioïle, d'un agent d'induction et de succinylcholine. La fréquence des complications au niveau des voies aériennes est trop basse pour justifier un changement de notre pratique.

Rapid sequence induction (RSI) is applied commonly to decrease the risk of regurgitation of gastric contents and aspiration pneumonitis in patients undergoing emergency surgery. The purpose of the technique is to minimize the time interval between loss of protective airway reflexes and the moment the airway is secured. The introduction of succinylcholine in 1951 and the description of cricoid pressure by Sellick ${ }^{1}$ in 1961 have been important milestones in anesthesia. Important steps in the RSI technique include preoxygenation, cricoid pressure, a rapid induction with a pre-determined dose of hypnotic agent and neuromuscular blocking agent, omission of manual ventilation, and intubation with a cuffed tracheal tube. ${ }^{2}$ Variants of the technique include withholding cricoid pressure, ${ }^{3}$ addition of an opioid and slower injection of induction drugs (modified RSI), ${ }^{4}$ and gentle application of manual ventilation. ${ }^{1}$

Although RSI is a widely accepted technique, it does have disadvantages and is associated with a few controversies. First, there are no studies demonstrating the effectiveness of RSI, with or without cricoid pressure. ${ }^{3,4}$ Second, cricoid pressure is a difficult technique to master. ${ }^{3,5}$ Third, in cases of failure to intubate, all advantages provided by the technique are likely lost. ${ }^{6}$ Fourth, since the doses of medications are predetermined and cannot be titrated to effect, there is a risk of under- or over-treatment, with adverse hemodynamic consequences and/or inadequate anesthesia. Finally, there is no universal agreement on the indications for RSI. The risk of aspiration is well recognized, even in Cesarean delivery, but surveys indicate that RSI practice varies widely. ${ }^{6-8}$ In emergency abdominal surgery, there is evidence of increased risk of regurgitation and vomiting in the presence of bowel obstruction, ${ }^{9,10}$ but only a few cases of aspiration have been reported in the setting of appendectomies. ${ }^{9,10}$ There are no data on stomach contents in patients with acute appendicitis.

Considering the lack of solid scientific evidence for the benefits of RSI, there appeared to be a need to reassess the use of the technique. However, a change in practice would be indicated only if RSI happened to be associated with additional risk over an alternate technique. Therefore, data on the actual use of RSI and its complications would be needed. To accomplish this objective, we chose appendectomy, a single but common surgical procedure wherein "full stomach considerations" might apply. Also, we preferred to complete a retrospective study in a teaching institution rather than a survey, because the former would be more likely to reveal the particulars of each case. Our primary objective was to determine how often RSI was applied in patients presenting with acute appendicitis. Our secondary objectives were to examine: whether a difficult intubation was anticipated, the induction agents and neuromuscular blocking agents used and their respective doses, how the airway was secured, and the incidence of airway and hemodynamic complications.

\section{Methods}

The protocol was approved by the Research Ethics Committee of Maisonneuve-Rosemont Hospital. This research project was a retrospective study based on the anesthetic and medical records of patients who underwent appendectomies in a one-year period from September 1, 2004 to August 31, 2005 at the Maisonneuve-Rosemont Hospital, a University of Montreal affiliated teaching hospital. An Excel spreadsheet was prepared based on the results of a one-month pilot study conducted on the appendectomies performed in August 2004. Inclusion criteria were patients from all ages and sexes who were admitted to hospital from the emergency department and whose preoperative and postoperative diagnosis was acute appendicitis. Exclusion criteria were patients already in hospital whose postoperative diagnosis was not acute appendicitis or who underwent other surgical procedures in the same setting.

Information was retrieved from the hand-written anesthetic records during 2006. Standard demographic data were collected. The pre-anesthetic evaluation sheet was screened for the American Society of Anesthesiologists (ASA) physical status, smoking history, and Mallampati airway assessment, as modified by Samsoon and Young. ${ }^{11}$

Each anesthetic record was examined for anesthesia type (regional $v s$ general). If general anesthesia was chosen, we 
noted the type of airway device used. Preoxygenation was presumed to have taken place if it was mentioned in the chart. If tracheal intubation was performed, RSI was considered as having been applied if any of the terms "rapid sequence" or "Sellick" or "cricoid pressure" were written. Direct laryngoscopy without any other aid was presumed unless other methods were mentioned (stylet, videolaryngoscope, Trachlight ${ }^{\mathrm{TM}}$, etc.). The medications used for induction of anesthesia and their respective doses were noted. The anesthetic record contains a tick box for easy or difficult intubation and an area to indicate the 4-grade Cormack and Lehane ${ }^{12}$ view of the glottis. These items were noted for each patient. Any hand-written comment on airway complications was noted, such as number of attempts, failed intubation, use of alternate airway methods, or aspiration and desaturation. Aspiration was presumed likely if there was documentation of regurgitation at laryngoscopy, if "aspiration" was written as a diagnosis on the anesthetic record in the recovery room, or if there was follow up or treatment for aspiration pneumonitis in the postoperative period. Hypotension and hypertension were defined as a systolic blood pressure $<80 \mathrm{mmHg}$ and $>160 \mathrm{mmHg}$, respectively, in the first 20 min following induction of anesthesia. Agents administered to treat these hemodynamic alterations were noted.

The anesthesia record was also screened to ascertain the drugs used to maintain anesthesia and muscle relaxation and the drugs used to reverse neuromuscular blockade. Time of extubation was recorded, whether performed in the operating room or in the recovery room. Also, all airway complications written on the anesthesia or recovery room chart were noted.

\section{Statistics}

The primary outcome measurement was the number of times RSI was used. We selected the number of charts to review on the basis that any technique used at a frequency $>1 \%$ would have a $95 \%$ chance of appearing at least once. The calculated number was 300 . Since this result corresponded approximately to the number of appendectomies performed in a one-year period, charts for a one-year period were examined. Continuous data are presented as means and standard deviation (SD). Incidences of a particular event are presented as a number of cases and percentage.

\section{Results}

Two hundred sixty-four patients were eligible for the study, but only 250 patients fit our inclusion criteria (Figure 1). General anesthesia with tracheal intubation was performed in 248 cases, and spinal anesthesia was performed in two

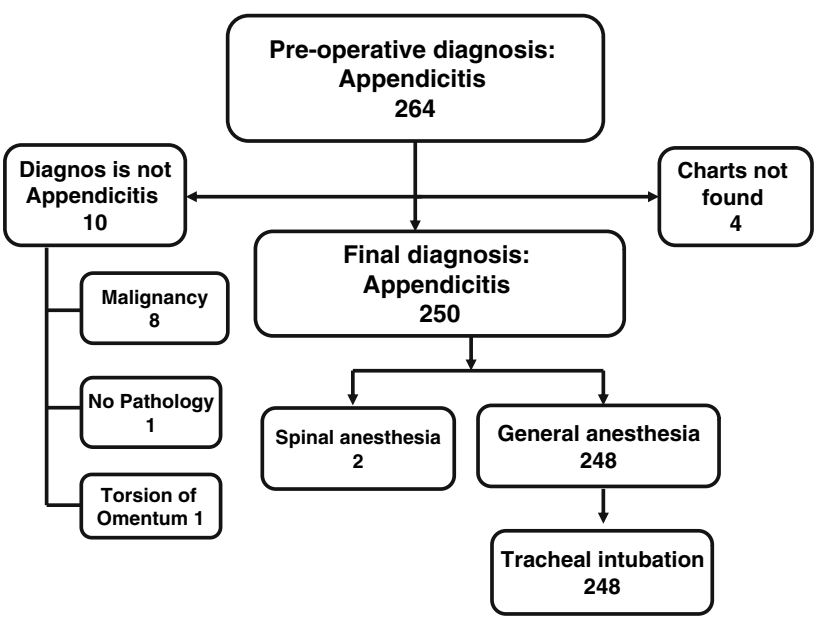

Fig. 1 Surgical diagnosis and type of anesthesia. Numbers represent number of patients

cases. The patients' characteristics are presented in Table 1 . There were 72 patients (29\%) aged $19 \mathrm{yr}$ and under and 87 patients (35\%) aged 20-39 yr. Forty percent of the patients were women, and five of these $(5 \%)$ were pregnant. Sixty-eight patients $(27 \%)$ were tobacco smokers, $13(5 \%)$ smoked marijuana, and five (2\%) took other recreational drugs.

The Mallampati score was present in 239 patient charts (95\%), and the Cormack grade of glottis view was reported in $232(94 \%)$ of the charts. A Mallampati 1 or 2 classification was found in 224 patients (93.3\%), and the remaining 15 patients $(6.7 \%)$ had a grade 3 classification. A nerve stimulator was used in $96.3 \%$ of patients.

Agents used for induction and their doses are shown in Table 2. The typical agents administered were an opioid (98\% of patients), propofol (98\%), and a neuromuscular blocking agent (99.6\%). Succinylcholine was administered in $80 \%$ of cases, and $96 \%$ of these patients received precurarization. Rocuronium was used in the remaining $19 \%$ of cases, and only $17 \%$ of these patients received a priming dose. Management of muscle relaxation is illustrated in Figure 2. Anticholinesterase agents were given to 218 of the 227 patients who received a non-depolarizing neuromuscular blocking agent.

The anesthetic chart indicated that preoxygenation was applied in most patients (94\%). The terms "rapid sequence", "Sellick", and/or "cricoid pressure" were mentioned in $81 \%$ of patients' charts (Table 3). A Cormack grade 3 view of the glottis was mentioned in five $(2 \%)$ of the 232 cases $(94 \%)$ where a Cormack view was documented, and no grade 4 view was reported. Tracheal intubation was evaluated as "easy" in 245 of 248 patients, including two patients with a Cormack grade 3. Direct laryngoscopy was used in 241 of these cases and a videolaryngoscope was used in 4 cases. A stylet was used with 
Table 1 Demographic data $(n=250)$

ASA $=$ American Society of Anesthesiologists;

$\mathrm{OR}=$ operating room;

$\mathrm{SD}=$ standard deviation

\begin{tabular}{lll}
\hline Item & Value & $\begin{array}{l}\text { Number }(\%) \\
\text { of charts where } \\
\text { item mentioned }\end{array}$ \\
\hline Gender (M/F) & & $250(100 \%)$ \\
Age $(y r)($ mean $\pm \mathrm{SD})$ & $150 / 100(60 \% / 40 \%)$ & $250(100 \%)$ \\
Weight $(\mathrm{kg})($ mean $\pm \mathrm{SD})$ & $29.5 \pm 18.6$ & $220(88 \%)$ \\
ASA physical status $(\mathrm{I}-\mathrm{II} / \mathrm{III}-\mathrm{IV}-\mathrm{V})$ & $66.6 \pm 19.6$ & $116(46 \%)$ \\
Triage to OR time $(\mathrm{hr})(\mathrm{mean} \pm \mathrm{SD})$ & $108 / 8$ & $245(98 \%)$ \\
Duration of surgery $(\mathrm{min})(\mathrm{mean} \pm \mathrm{SD})$ & $12.3 \pm 10.4$ & $245(98 \%)$ \\
Duration of recovery room stay $(\mathrm{min})($ mean $\pm \mathrm{SD})$ & $50 \pm 27$ & $241(97 \%)$ \\
\hline
\end{tabular}

Table 2 Agents used for induction of anesthesia $(n=248)$

\begin{tabular}{lcc}
\hline $\begin{array}{l}\text { Agents used } \\
\text { at induction }\end{array}$ & $\begin{array}{l}\text { Number of } \\
\text { cases } \%)\end{array}$ & $\begin{array}{l}\text { Dose }\left(\mathrm{mg} \cdot \mathrm{kg}^{-1}\right) \\
\left(\mu \mathrm{g} \cdot \mathrm{kg}^{-1} \text { for opioids) }\right. \\
\text { Mean } \pm \mathrm{SD}\end{array}$ \\
\hline Opioids & $244(98 \%)$ & \\
Fentanyl & $184(74 \%)$ & $2.84 \pm 1.01$ \\
Sufentanil & $59(24 \%)$ & $0.54 \pm 0.76$ \\
Alfentanil & $17(11 \%)$ & $11.40 \pm 4.67$ \\
Remifentanil & $23(9 \%)$ & $1.63 \pm 1.04$ \\
Two or more & $37(15 \%)$ & - \\
Induction agents & $248(100 \%)$ & \\
Propofol & $243(97 \%)$ & $2.64 \pm 0.81$ \\
Thiopental & $5(2 \%)$ & $4.43 \pm 1.43$ \\
Ketamine & $1(0.4 \%)$ & - \\
Neuromuscular & $247(99.6 \%)$ & \\
$\quad$ blocking agents & $199(80 \%)$ & $1.97 \pm 0.40$ \\
Succinylcholine & $192 / 199(96 \%)$ & $0.044 \pm 0.020$ \\
With rocuronium & & \\
precurarization & $48(19 \%)$ & $0.73 \pm 0.19$ \\
Rocuronium & $8 / 48(17 \%)$ & $0.042 \pm 0.19$ \\
$\begin{array}{l}\text { Priming } \\
\text { Other }\end{array}$ & $122(49 \%)$ & $1.15 \pm 0.49$ \\
Lidocaine & & \\
\hline SD standar & & \\
\hline
\end{tabular}

$\mathrm{SD}=$ standard deviation

direct laryngoscopy in 20 patients and no aid was used in the remaining patients. Tracheal intubation was noted as "difficult" in three patients (1.2\%) who had grade 1 or 2 Mallampati scores. The alternatives used for tracheal intubation in these patients included a Trachlight ${ }^{\mathrm{TM}}$ and a fibrescope in one case, a stylet in another, and an unspecified technique in the third case.

Oxygen desaturation at intubation was mentioned in only one patient (Table 3). This patient, a 102-kg male smoker, ASA physical status III with a grade 1 Mallampati score, underwent an easy tracheal intubation and experienced a brief episode of desaturation to $85 \%$. Hypotension occurred in 66 patients (27\%), 31 of whom (47\%) required treatment. Hypertension occurred in 25 patients, only two of whom (8\%) required treatment. There were no episodes

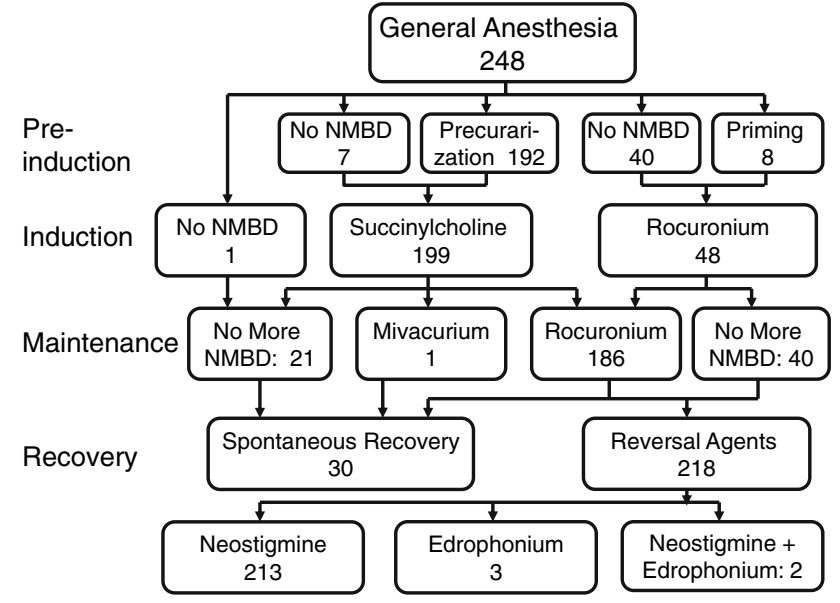

Fig. 2 Management of muscle relaxation and reversal of neuromuscular blockade. Numbers represent number of patients

Table 3 Events at intubation and emergence

\begin{tabular}{lll}
\hline Event & Number of patients & $\%$ \\
\hline Preoxygenation & 234 & $94 \%$ \\
Rapid Sequence Induction & 200 & $81 \%$ \\
Intubation Technique & & \\
Direct Laryngoscopy & 221 & $89 \%$ \\
Stylet & 21 & $8 \%$ \\
Videolaryngoscope & 4 & $2 \%$ \\
Fibreoptic & 1 & $0.4 \%$ \\
Trachlight & 1 & $0.4 \%$ \\
Not indicated & 1 & $0.4 \%$ \\
Complications & & \\
Difficult Intubation & 3 & $1.2 \%$ \\
Desaturation at induction & 1 & $0.4 \%$ \\
Aspiration & 0 & $0 \%$ \\
Hypotension (BP < 80) & 66 & $27 \%$ \\
Requiring treatment & $31 / 66$ & $47 \%$ \\
Hypertension (BP $>$ 160) & 25 & $10 \%$ \\
Requiring treatment & $2 / 25$ & $8 \%$ \\
Desaturation at emergence & 3 & $1.2 \%$ \\
\hline BP & &
\end{tabular}

$\mathrm{BP}=$ systolic blood pressure 
of aspiration mentioned in the anesthetic charts nor were there any documented pneumonias by the surgical treating team once the patients were transferred to the ward.

Extubation was performed in the operating room in 39\% of cases and in the recovery room in $60 \%$ of the cases. Two patients $(1 \%)$ were transferred directly to the intensive care unit (ICU) or to the coronary care unit (CCU), respectively. Three patients $(1.2 \%)$ had oxygen desaturation in the recovery room: one patient desaturated to $90 \%$ and was treated with oxygen and an anticholinesterase agent; another patient desaturated to $88 \%$, and no further comments were written; and a third subject, who was obese and had chronic obstructive pulmonary disease, had a "persistent desaturation at $88 \%$ ", which necessitated endotracheal suctioning and continuous positive airway pressure for 2.5 hr before extubation. Regurgitation or aspiration was not mentioned in this patient's chart.

One patient was transferred to the ICU because she was in septic shock, and one patient was transferred to the CCU because of suspicion of acute coronary syndrome, which proved unfounded. The only mortality was that of a 70-yrold man, ASA physical status III, who died ten days postoperatively after suffering a massive myocardial infarction with failed reperfusion and subsequent stroke. Nothing in particular was indicated in his anesthetic record.

\section{Discussion}

In our institution, which is a teaching hospital, general anesthesia with tracheal intubation was the preferred approach for the vast majority of patients scheduled for emergency appendectomy. The charts indicated that preoxygenation was applied in $94 \%$ of cases, while RSI was chosen in $81 \%$. It is possible that these techniques were used in a larger proportion of patients, as they may have been performed but not charted. Since this study was retrospective and there was no specific entry for "rapid sequence induction", "cricoid pressure", or "Sellick" in the chart, it was not possible to determine whether "rapid sequence induction" also included cricoid pressure or viceversa. However, if one of these terms was entered, it was presumed that consideration was given to the risk of aspiration. Virtually all tracheal intubations were performed under direct laryngoscopy, with a stylet used in some cases. Of note, the laryngeal mask airway $\left(\mathrm{LMA}^{\mathrm{TM}}\right)$ was not used in any subject, although we found two LMA cases during the one-month pilot study. The use of LMAs for appendectomies might be a common practice in other parts of the world. A French survey reported that use of tracheal intubation or LMA was used in only $84 \%$ of children undergoing appendectomy. ${ }^{13}$
Airway assessment with Mallampati score was present in the anesthetic charts of $95.6 \%$ of patients. All three difficult intubations were missed by the Mallampati score, emphasizing its limited sensitivity and specificity ${ }^{14}$ and the need for additional screening measures. The incidence of tracheal intubations that were considered difficult was $1.2 \%$, which is less than the $5.8 \%$ incidence reported in a recent meta-analysis of 35 trials. ${ }^{14}$

The only two descriptions of RSI reported initially were the rapid administration of an induction agent and a neuromuscular blocking drug ${ }^{15}$ however, recent surveys suggest that opioids are given frequently in the RSI setting. ${ }^{2,7}$ In a review of studies done on neuromuscular blocking agents for RSI, induction techniques were divided into "True RSI" and "Modified RSI", both subdivided into opioid and opioid-free regimens. ${ }^{16}$ However, in that review, most of the studies enrolled elective patients in whom RSI was simulated rather than emergency patients suspected of having a full stomach. In the present study, most anesthesiologists (98\%) chose to administer opioids. Propofol was the hypnotic agent of choice $(97.2 \%)$ and was preferred to thiopental, which is the traditional agent recommended for RSI. In 1999, most British anesthesiologists surveyed (96\%) reported using thiopental for $\mathrm{RSI}^{7}{ }^{7}$ but in two recent studies ${ }^{17,18}$ on RSI in emergency patients, the induction agent was propofol $\left(1.5-3 \mathrm{mg} \cdot \mathrm{kg}^{-1}\right)$, which compares favourably with the mean dose administered here (2.64 $\left.\mathrm{mg} \cdot \mathrm{kg}^{-1}\right)$.

The preferred neuromuscular blocking drug for RSI was succinylcholine, which was used in $80 \%$ of cases. This is in line with traditional recommendations and with the results of surveys. ${ }^{2,7,15}$ The mean dose was close to $2.0 \mathrm{mg} \cdot \mathrm{kg}^{-1}$, which seems appropriate since precurarization was used in most instances. The dose in this case is probably equivalent to $1.0 \mathrm{mg} \cdot \mathrm{kg}^{-1}$ without precurarization. ${ }^{19,20}$ For induction, precurarization was almost systematic (96\%), but priming was present in only $17 \%$ of cases. The average dose $\left(0.044 \mathrm{mg} \cdot \mathrm{kg}^{-1} \pm 0.019\right)$ was higher than the recommended $10 \%$ of the $\mathrm{ED}_{95}\left(0.03 \mathrm{mg} \cdot \mathrm{kg}^{-1}\right){ }^{19}$

Hypotension occurred in $24 \%$ of cases, and only $47 \%$ of these required treatment. Hypertension occurred less often (10\%) than hypotension, which may indicate a tendency towards an overestimated dose of the hypnotic agent rather than an underestimated dose. It is possible that some of these hemodynamic events were not due directly to RSI per se. Larsen et al. ${ }^{18}$ who used alfentanil $\left(10-20 \mu \mathrm{g} \cdot \mathrm{kg}^{-1}\right)$ and propofol (2-3 $\left.\mathrm{mg} \cdot \mathrm{kg}^{-1}\right)$ at induction in the RSI setting, also reported more hypotension than hypertension. Half of their patients had acute appendicitis.

Our study has some limitations. First, it is a retrospective study. However, most of the data regarding RSI in the literature have been obtained through surveys, ${ }^{2,7}$ and respondents might answer what they consider as right 
rather than what they would do in a given situation. A retrospective study is more likely to reflect what was done, and it is probably better than a prospective survey in this case, because practitioners might change their practice if they know a study is taking place. Considering the wide acceptance of RSI among our anesthesiologists, it would have been difficult to involve them in a prospective randomized controlled study comparing RSI with an alternate technique. Thus, a retrospective study is probably the best design to obtain data on what was actually done.

The second limitation is that all the data used are directly dependent on the anesthetic record. The frequency of the studied events was probably underestimated, since it is likely that some actions were performed and not charted. Thus, if anything, preoxygenation and RSI may have been performed more frequently than the results suggest $(94 \%$ and $81 \%$, respectively), which indicates widespread acceptance of these techniques. On the other hand, the incidence of difficult intubation and/or desaturation may have been underestimated. However, the airway was managed successfully in all cases. A third limitation is that it is not certain that our conclusions are applicable to surgeries other than appendectomies. Fourth, the study was conducted in one teaching hospital, and it is not clear how RSI is used in other centres.

A randomized controlled study designed to demonstrate the effectiveness of RSI in preventing pulmonary aspiration would require many thousands of patients because the incidence of aspiration is low. ${ }^{4}$ The present study also shows that a trial designed to demonstrate that RSI is associated with more airway complications than other techniques would require thousands of patients, given the low incidence of such complications.

Emergency surgery is considered as a risk factor for aspiration, and surveys indicate that the incidence of pulmonary aspiration is greater in patients presenting for emergency surgery. ${ }^{10,21,22}$ However, the risk may not be the same for all emergency procedures. Before RSI became a widespread practice, abdominal cases comprised 71 of the 110 fatal cases of regurgitation and vomiting in a report of deaths attributed to anesthesia. ${ }^{9}$ However, appendicitis is not cited in that study, although there were ten cases of peritonitis, the origin of which is not specified. In subsequent surveys, Olsson et al. mentioned appendicitis in five cases among 83 reports of aspiration. ${ }^{10}$ In the series of 24 cases of aspiration in children published by Warner et al., there were no cases of appendicitis. ${ }^{21}$ Similarly, appendicitis is not part of the diagnoses listed by Sakai et $a l .^{23}$ (23 cases) and Neelakanta et al. $^{24}$ (23 cases). Thus, aspiration in patients presenting for appendix surgery is a rare event, and it is not surprising that none were found in our study. However, it is unclear whether the incidence is low because of a low baseline risk or because of the effectiveness of RSI. In the present study, anesthesiologists mentioned using RSI in $81 \%$ of cases. In a recent survey conducted in Wales, $94 \%$ of respondents said they would choose an RSI technique for an emergency appendectomy. $^{25}$ Tracheal intubation appears to protect patients against aspiration. In a recent French retrospective study, 36 cases of aspiration were found. Twenty-five of these did not undergo RSI with tracheal intubation. ${ }^{22}$ In an Australian study of 133 cases of aspiration occurring during anesthesia, the airway was managed with a tracheal tube in only eight cases, an LMA in 23 cases, and a face mask in most of the remaining cases. ${ }^{26}$

In conclusion, while the evidence regarding the safety and efficacy of RSI for appendectomies is weak at best, the present study suggests that the incidence of airway complications associated with RSI does not appear to be greater than in the general population. Hemodynamic consequences are more frequent, but minor. Therefore, it seems reasonable to continue to apply RSI for appendectomies and perhaps for other procedures where a "full stomach" might be a consideration. There is no need to recommend a change in practice.

Funding sources None.

Conflicts of interest None declared.

\section{References}

1. Sellick BA. Cricoid pressure to control regurgitation of stomach contents during induction of anaesthesia. Lancet 1961; 278: 404-6.

2. Morris J, Cook TM. Rapid sequence induction: a national survey of practice. Anaesthesia 2001; 56: 1090-7.

3. Brimacombe JR, Berry AM. Cricoid pressure. Can J Anaesth 1997; 44: 414-25.

4. Neilipovitz DT, Crosby ET. No evidence for decreased incidence of aspiration after rapid sequence induction. Can J Anesth 2007; 54: 748-64.

5. Herman NL, Carter B, Van Decar TK. Cricoid pressure: teaching the recommended level. Anesth Analg 1996; 83: 859-63.

6. Thwaites AJ, Rice CP, Smith I. Rapid sequence induction: a questionnaire survey of its routine conduct and continued management during a failed intubation. Anaesthesia 1999; 54: 376-81.

7. Tourtier JP, Compain M, Petitjeans F, et al. Acid aspiration prophylaxis in obstetrics in France: a comparative survey of 1998 vs. 1988 French practice. Eur J Anaesthesiol 2004; 21: 89-94.

8. Han TH, Brimacombe J, Lee EJ, Yang HS. The laryngeal mask airway is effective (and probably safe) in selected healthy parturients for elective cesarean section: a prospective study of 1067 cases. Can J Anesth 2001; 48: 1117-21.

9. Edwards G, Morton HJ, Pask EA, Wylie WD. Deaths associated with anaesthesia; a report on 1, 000 cases. Anaesthesia 1956; 11: 194-220.

10. Olsson GL, Hallen B, Hambraeus-Jonzon K. Aspiration during anaesthesia: a computer-aided study of 185, 358 anaesthetics. Acta Anaesthesiol Scan 1986; 30: 84-92.

11. Samsoon GL, Young JR. Difficult tracheal intubation: a retrospective study. Anaesthesia 1987; 42: 487-90. 
12. Cormack RS, Lehane J. Difficult tracheal intubation in obstetrics. Anaesthesia 1984; 39: 1105-11.

13. Ecoffey $C$, Auroy $Y$, Pequignot $F$, et al. A French survey of paediatric airway management use in tonsillectomy and appendicectomy. Paediatr Anaesth 2003; 13: 584-8.

14. Shiga T, Wajima Z, Inoue T, Sakamoto A. Predicting difficult intubation in apparently normal patients: a meta-analysis of bedside screening test performance. Anesthesiology 2005; 103: 429-37.

15. Stept WJ, Safar P. Rapid induction-intubation for prevention of gastric-content aspiration. Anesth Analg 1970; 49: 633-6.

16. Lysakowski C, Suppan L, Czarnetzki C, Tassonyi E, Tramer MR. Impact of the intubation model on the efficacy of rocuronium during rapid sequence intubation: systematic review of randomized trials. Acta Anaesthesiol Scand 2007; 51: 848-57.

17. Sluga M, Ummenhofer W, Studer W, Siegemund M, Marsch SC. Rocuronium versus succinylcholine for rapid sequence induction of anesthesia and endotracheal intubation: a prospective, randomized trial in emergent cases. Anesth Analg 2005; 101: 1356-61.

18. Larsen $P B$, Hansen EG, Jacobsen $L S$, et al. Intubation conditions after rocuronium or succinylcholine for rapid sequence induction with alfentanil and propofol in the emergency patient. Eur $\mathbf{J}$ Anaesthesiol 2005; 22: 748-53.

19. Schreiber JU, Lysakowski C, Fuchs-Buder T, Tramer MR. Prevention of succinylcholine-induced fasciculation and myalgia: a meta-analysis of randomized trials. Anesthesiology 2005; 103: 877-84.

20. Szalados JE, Donati F, Bevan DR. Effect of d-tubocurarine pretreatment on succinylcholine twitch augmentation and neuromuscular blockade. Anesth Analg 1990; 71: 55-9.

21. Warner MA, Warner ME, Weber JG. Clinical significance of pulmonary aspiration during the perioperative period. Anesthesiology 1993; 78: 56-62.

22. Landreau B, Odin I, Nathan N. Pulmonary aspiration: epidemiology and risk factors (French). Ann Fr Anesth Reanim 2009; 28: 206-10.

23. Sakai T, Planinsic RM, Quinlan JJ, Handley LJ, Kim TY, Hilmi $I A$. The incidence and outcome of perioperative pulmonary aspiration in a university hospital: a 4-year retrospective analysis. Anesth Analg 2006; 103: 941-7.

24. Neelakanta $G$, Chikyarappa A. A review of patients with pulmonary aspiration of gastric contents during anesthesia reported to the Departmental Quality Assurance Committee. J Clin Anesth 2006; 18: 102-7.

25. Koerber JP, Roberts GE, Whitaker R, Thorpe CM. Variation in rapid sequence induction techniques: current practice in Wales. Anaesthesia 2009; 64: 54-9.

26. Kluger MT, Short TG. Aspiration during anaesthesia: a review of 133 cases from the Australian Anaesthetic Incident Monitoring Study (AIMS). Anaesthesia 1999; 54: 19-26. 